\title{
The Use of Matrix Technique in an Analysis of Atta Personal Pronouns
}

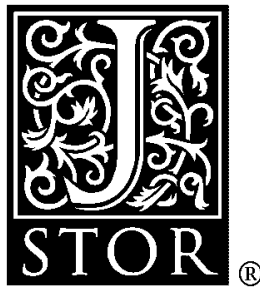

\author{
Ruth Lusted; Claudia Whittle; Lawrence A. Reid
}

Oceanic Linguistics, Vol. 3, No. 1, Papers in Philippine Linguistics. (Summer, 1964), pp. $138-160$.

Stable URL:

http://links.jstor.org/sici?sici=0029-8115\%28196422\%293\%3A1\%3C138\%3ATUOMTI\%3E2.0.CO\%3B2-3

Oceanic Linguistics is currently published by University of Hawai'i Press.

Your use of the JSTOR archive indicates your acceptance of JSTOR's Terms and Conditions of Use, available at http://www.jstor.org/about/terms.html. JSTOR's Terms and Conditions of Use provides, in part, that unless you have obtained prior permission, you may not download an entire issue of a journal or multiple copies of articles, and you may use content in the JSTOR archive only for your personal, non-commercial use.

Please contact the publisher regarding any further use of this work. Publisher contact information may be obtained at http://www.jstor.org/journals/uhp.html.

Each copy of any part of a JSTOR transmission must contain the same copyright notice that appears on the screen or printed page of such transmission.

The JSTOR Archive is a trusted digital repository providing for long-term preservation and access to leading academic journals and scholarly literature from around the world. The Archive is supported by libraries, scholarly societies, publishers, and foundations. It is an initiative of JSTOR, a not-for-profit organization with a mission to help the scholarly community take advantage of advances in technology. For more information regarding JSTOR, please contact support@jstor.org. 
THE USE OF MATRIX TECHNIQUE IN AN ANALYSIS OF ATTAL PERSONAL PRONOUNS

\author{
Ruth Lusted, Claudia Whittle, \\ and Lawrence A. Reid
}

0. Introduction

1. Permutation and Conflation

1. 1 Listing of Pronouns

1. 2 Stages in Pronoun Matrix Permutation

1. 3 Conflation

2. Semantic Microanalysis

2. 1 Formatives for Person and Number

2. 2. Formatives of Aspect and Grammatical Relationships

3. Summary

0. Introduction. All Philippine languages have multiple pronoun sets, differing in distribution within the clause, and differing in internal complexity. Traditionally, 2 pronoun sets have been listed and their distribution stated, but few attempts have been made to describe their internal structuring. Smearing of morpheme boundaries has made conventional morpheme analysis of the pronouns a difficult and often unproductive exercise. ${ }^{3}$ It will be demonstrated in this paper, however, that by using the techniques of matrix permutation and conflation, ${ }^{4}$ the ranking of pronouns and a display of their internal structure is entirely possible. The purpose of this paper is, first, to demonstrate how this was accomplished for the Atta pronouns, and second, to show how on the basis of these matrices meanings can be attributed to each of the pronoun formatives. 5

1. Permutation and Conflation. First a conventional listing of Atta pronouns is given. Then, stages in the matrix permutations 
of the pronouns are described, and finally the resultant matrix is conflated to reveal ranking of the pronouns and the patterning of their formatives.

1. 1 Listing of Pronouns. Four sets of personal pronouns occur in Atta. ${ }^{6}$ Set I pronouns occur as topic of a clause, Set II as source, Set III as oblique, and Set IV as emphasis (see Matrix 1). In the matrices person 1 represents speaker when singular, speaker and companion(s) when plural. Person 1,2 represents speaker and addressee in the singular; speaker, addressee, and companion(s) of either or both in the plural. 7 Person 2 represents addressee in the singular, addressees in the plural. Persona 3 represents referent when singular, referents when plural. Matrix 1 consists of a conventional listing of the pronouns.

Matrix 1. 8

Set I

$$
\text { Singular Plural }
$$

1

1, 2

2

3

Set II

1

1,2

2

3

Set III

\section{1}

1,2

2

3

Set IV

1

1,2

2

3

aq
itta
ka
$\#$

$\mathrm{ku}$

ta

$\mathrm{mu}$

na

nikaan

nitta

nikaw

kuna

sikaan

sitta

sikaw

aggina kami

ittam

kayu

ira

$\mathrm{mi}$

tam

naw

da

nikami

nittam

nikayu

nira

sikami

sittam

sikayu

aggira 
1. 2 Stages in Pronoun Matrix Permutation. 9 From the above listing of the pronouns Matrix 2a was set up. The four sets form the columns; person forms the rows with singular persons grouped preceding plural persons. The formatives ni in Set III and si in Set IV become apparent in Matrix 2a and these formatives are shown in the abstracted formative matrix $2 \mathrm{~b}$. However, the ni block of III is broken by the occurrence of ku in s 3 and the si block of IV is broken by ag in s 3 and $\mathrm{p} 3$.

Matrix 2a.

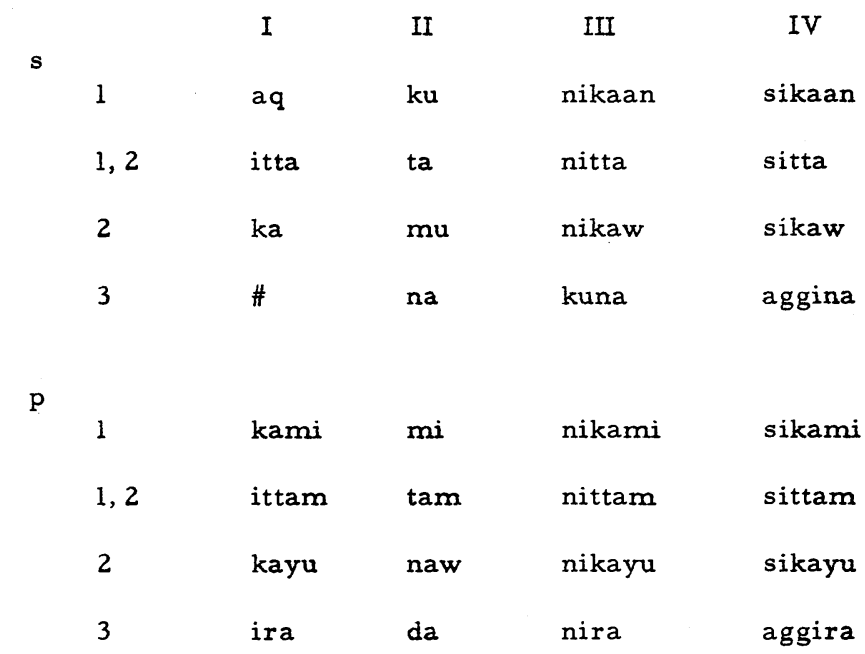

Matrix 2b.

III IV

s

1

1,2

2

3

$\mathrm{p}$

1

1,2

2

3

\begin{tabular}{l|l} 
ni & si \\
ni & si \\
ni & si \\
\hline ku & ag \\
\hline ni & si \\
ni & si \\
ni & si \\
ni & ag
\end{tabular}


In order to bring the si, ni, ag, and $\mathrm{ku}$ formatives into unbroken blocks, Matrix 2a was then rearranged so that the singular and plural categories appear in columns instead of rows (Matrix 3a). This brings together the ni block in Set III, all persons except s 3 , which itself forms a block of ku; the si block in Set IV, persons 1 , 1,2, and 2; and the ag block in Set IV, person 3 (see abstracted formative matrix $3 b$ ).

Matrix 3a.

\begin{tabular}{|c|c|c|c|c|c|c|c|}
\hline $\mathbf{s}$ & $\mathrm{p}$ & $\mathrm{s}$ & $\mathrm{p}$ & $\mathrm{s}$ & $\mathrm{p}$ & $\mathrm{s}$ & $\mathrm{p}$ \\
\hline $\mathrm{aq}$ & kami & $\mathrm{ku}$ & $\mathrm{mi}$ & nikaan & nikami & sikaan & sikami \\
\hline itta & ittam & ta & tam & nitta & nittam & sitta & sittam \\
\hline $\mathrm{ka}$ & kayu & $\mathrm{mu}$ & naw & nikaw & nikayu & sikaw & sikayu \\
\hline$\#$ & ira & na & da & kuna & nira & aggina & aggira \\
\hline
\end{tabular}

Matrix 3b.

III

$\begin{array}{lll} & \text { s } & \text { p } \\ 1 & & \text { ni } \\ 1,2 & \text { ni } & \text { ni } \\ 2 & \text { ni } & \text { ni } \\ 3 & \text { ku ni }\end{array}$

IV

\begin{tabular}{|cc} 
s & $\mathrm{p}$ \\
$\mathrm{si}$ & $\mathrm{si}$ \\
$\mathrm{si}$ & $\mathrm{si}$ \\
$\mathrm{si}$ & $\mathrm{si}$ \\
\hline $\mathrm{ag}$ & $\mathrm{ag}$
\end{tabular}

Having observed the patterns of pronoun-initial formatives in the columns of Matrix 3a, patterns were then seen emerging in pronoun-ending formatives in the rows, for example the formatives ta alternating with tam in person 1, 2, and the da and na formatives in person 3. Since these cannot be as readily seen in rows as in columns, it is advantageous to permute Matrix $3 a$ so that the persons are shown in columns and the sets in blocks of singular and plural are shown in rows (Matrix 4a). Notice also the regrouping of the singulars and plurals together, destroying for the moment the previous blocks of $\underline{\mathrm{si}}, \mathrm{ni}, \underline{\mathrm{ag}}$, and $\mathrm{ku}$, but bringing together new like-formatives. These formatives are seen in Matrix 4 b. 
Matrix 4a.
1
1,2
2
3

s

$\begin{array}{lrrrr}\text { I } & \text { aq } & \text { itta } & \text { ka } & \text { \# } \\ \text { II } & \text { ku } & \text { ta } & \text { mu } & \text { na } \\ \text { III } & \text { nikaan } & \text { nitta } & \text { nikaw } & \text { kuna } \\ \text { IV } & \text { sikaan } & \text { sitta } & \text { sikaw } & \text { aggina }\end{array}$

p

$\begin{array}{lrrrr}\text { I } & \text { kami } & \text { ittam } & \text { kayu } & \text { ira } \\ \text { II } & \text { mi } & \text { tam } & \text { naw } & \text { da } \\ \text { III } & \text { nikami } & \text { nittam } & \text { nikayu } & \text { nira } \\ \text { IV } & \text { sikami } & \text { sittam } & \text { sikayu } & \text { aggira }\end{array}$

Matrix 4b.

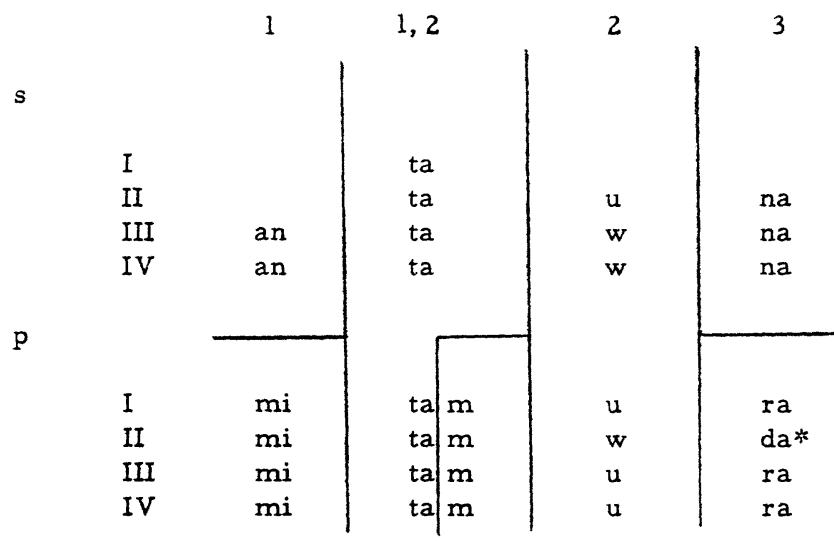

* The ra alternating with da occurs as a result of a morphophonemic change in which $\underline{d}$ becomes $\underline{r}$ following vowels.

A formative $\mathrm{ka}$ was then noted appearing interior in the composites of some cells of persons 1 and 2 vectors. To group these in a block, and also to place into adjacent columns the 
formative blocks already identified, Matrix $4 \mathrm{a}$ was permuted to group singular and plural with each person, and to cause person 1, 2 singular and plural to appear between person 2 and person 3 . This brings the ka block to the left of the matrix, occurring in persons 1 and 2 (Matrix 5a).

At this stage two more formatives may be identified and placed with ka in abstracted formative matrix $5 \mathrm{~b}$. These are $t$ (occurring as the final consonant of the first syllable of each of the bisyllabic pronouns of 1,2 person), and $g$ (occurring as the first consonant of the interior syllables of person 3 of Set IV).

Matrix 5a.

1

S

$s$

I aq

II $\mathrm{ku}$

III nikaan

IV sikaan sikami $\mathbf{s}$

$\mathrm{p}$

kami

$\mathrm{mi}$

nikami
2

1,2

p

p

s

$\left(\frac{10}{2}\right.$

ka kayu

mu naw

nikaw nikayu

sikaw sikayu itta ittam

ta tam

nitta nittam

sitta sittam
3

s $\quad p$

\# ira

na da

kuna nira

aggina aggira

Matrix 5b.

1

s
2

1,2

3

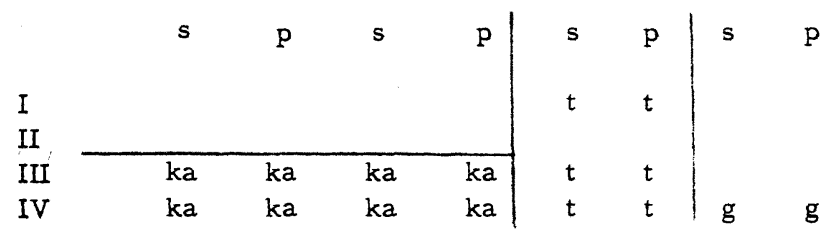

Examination of any of the preceding matrices reveals that Sets III and IV are more complex than Set I, and Set I in turn is more complex than Set II. A ranking of complexity becomes evident, suggesting the possibility of implications in the semantic analysis. In order to show clearly the ranking of complexity the rows I and II were interchanged (Matrix 6). 
Matrix 6.

1

$\mathrm{s}$

II $\quad \mathrm{ku}$

I

III nikaan nikami

IV sikaan sikami
2

$$
\mathrm{p}
$$

$\mathrm{s}$

$$
\mathrm{p}
$$

$\mathbf{s}$

1,2

3

It may be noted that columns $1 p, 1,2 s$, and 3p in Matrix 6 are more regular than the other columns in that the final syllable remains the same throughout the four sets. In Matrix 7 the regular columns are grouped on the left half of the matrix. In addition the rows are inverted to display a different perspective with greatest complexity appearing in the top row, least complexity in the bottom row.

Matrix 7.

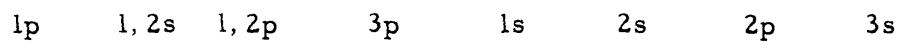

$\begin{array}{lrrrrrrrr}\text { IV } & \text { sikami } & \text { sitta } & \text { sittam } & \text { aggira } & \text { sikaan } & \text { sikaw } & \text { sikayu } & \text { aggina } \\ \text { III } & \text { nikami } & \text { nitta } & \text { nittam } & \text { nira } & \text { nikaan } & \text { nikaw } & \text { nikayu } & \text { kuna } \\ \text { I } & \text { kami } & \text { itta } & \text { ittam } & \text { ira } & \text { aq } & \text { ka } & \text { kayu } & \# \\ \text { II } & m i & \text { ta } & \text { tam } & \text { da } & \text { ku } & \text { mu } & \text { naw } & \text { na }\end{array}$

By Matrix 7 a grouping of regular columns was achieved.

It has lost however the regularity of rows with ka as seen in Matrix $5 \mathrm{a}$ and $5 \mathrm{~b}$. Because of the desire to preserve both the column regularity of Matrix 7 and the row regularity of Matrix 5, Matrix 8 was set up, in which the plural was placed before the singular with each person. 
Matrix 8.

1,2

3

$\begin{array}{llllllll}\mathrm{p} & \mathrm{s} & \mathrm{p} & \mathrm{s} & \mathrm{p} & \mathrm{s} & \mathrm{p} & \mathrm{s}\end{array}$

IV sikami sikaan sikayu sikaw sittam sitta aggira aggina

III nikami nikaan nikayu nikaw nittam nitta nira kuna

I kami aq kayu ka ittam itta ira \#

II $\mathrm{mi} \mathrm{ku}$ naw mu tam ta da na

1.3. Conflation. Having found by permutation all the apparent formative blocks in the matrices, including single-cell blocks containing ideal particles, ${ }^{11}$ a conflation of the formative blocks of Matrix 8 was made in Matrix 9 to portray the patterning and field structure of Atta personal pronouns. 
Matrix 9. Field Structure of Atta Personal Pronouns.

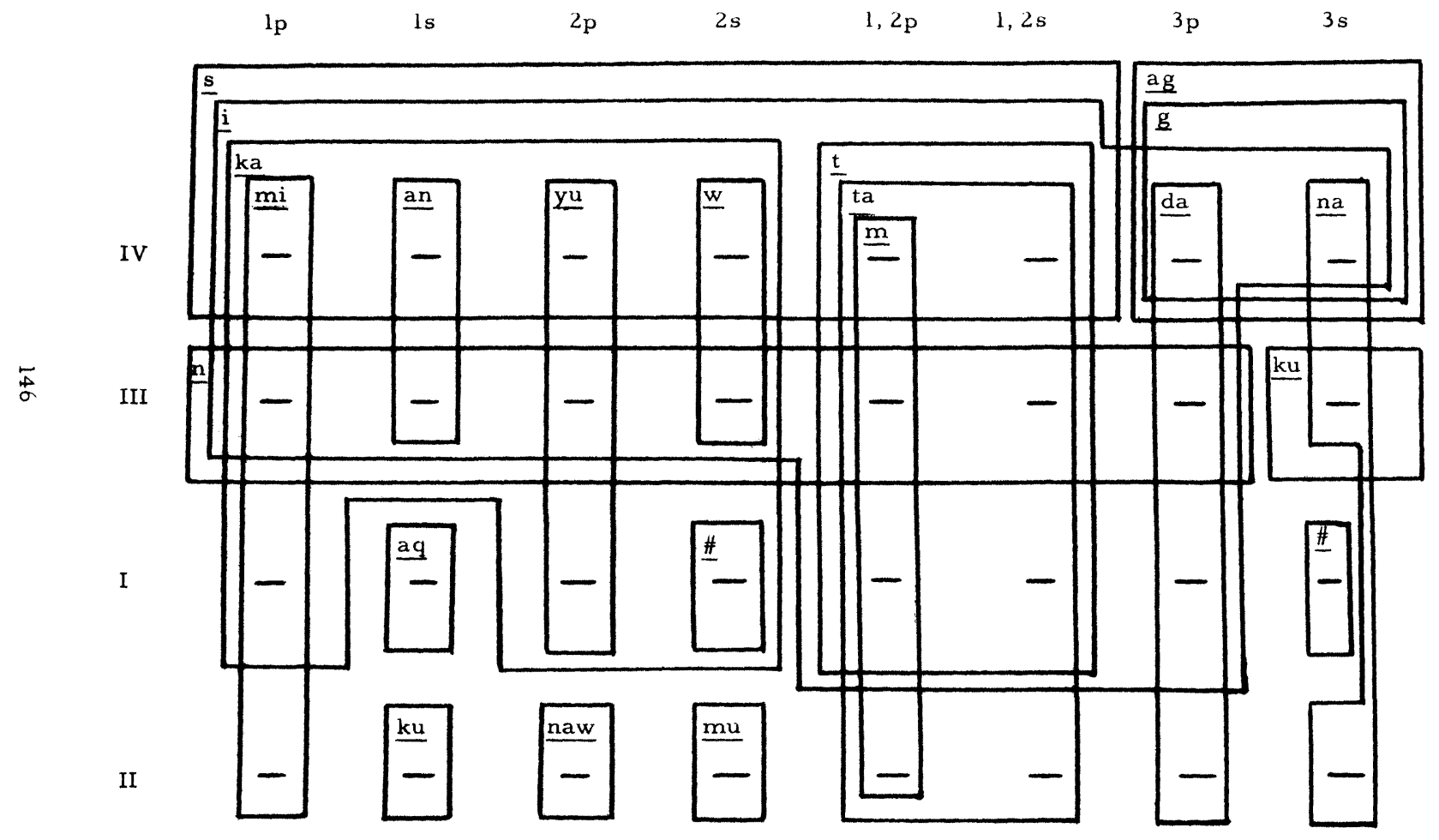


2. Semantic Microanalysis. Matrix 9 contains two complexities relevant to semantic description: (1) The columns are composed of two types of lexical categories--person and number. (2) The rows contain not lexical categories, but structural categories.

2. 1 Formatives for Person and Number. The simplest of the pronoun sets is Set II, which contains the semantic components of person and number. The pronouns of Set II (represented by one hyphen each in the bottom row of Matrix 9) are enclosed by only one block each, with the exception of person $1,2 \mathrm{p}$, which is also enclosed by an interior $\mathrm{m}$ block. Several of these blocks, i. e., $1 \mathrm{p}(\underline{\mathrm{mi}}), 1,2 \mathrm{p}$ (ta and $\mathrm{m}), 1,2 \mathrm{~s}(\mathrm{ta})$, and $3 \mathrm{p}(\mathrm{da})$, extend vertically without a break throughout the four sets of pronouns. The formatives in these vertical blocks contain the semantic components of person and number in the more complex pronoun sets as well. These are blocks of vector formatives, which are equivalent to conventional morphemes. ${ }^{13}$ The remaining verticals, i. e., from columns 1 , $2 \mathrm{p}, 2 \mathrm{~s}$, and 3s of Matrix 9, are broken in one or two places, reflecting alloformatives, or allomorphs, for person and number.

In describing the distribution of the person and number formatives, it is convenient to abstract pairs of submatrices for each pronoun set, separating the person and number formatives. This segmentation is perhaps of finer detail than that of previous conventional treatment.

Matrices 10 and 11 are abstracted submatrices for Sets III and IV, containing the formatives for person and number. Submatrices for these two pronoun sets are used to symbolize the emic norm of the various matrices of the four sets of pronouns for the following reasons: (1) Identical categories are found in each of the matrices. (2) There is a large percentage of identical formatives throughout the matrices. (3) Person and number formatives of Sets III and IV are homophonous throughout. (4) The alloformative variants of the person and number formatives in the four sets of pronouns are non-contrastive etic variants, conditioned in one of--or a combination of--the following ways: phonologically conditioned, or conditioned morphologically by the co-occurrence of morphemes of aspect or grammatical relationship, or indirectly conditioned by the distribution of each set within a different tagmemic slot.

Matrices of alloformatives for person and number in Sets I and II are not presented since they show only slight etic veriation 
from the norm shown in Matrices 10 and 11 . However, in the textual description of the matrices for Sets III and IV, variations of the matrices for Sets I and II will be stated.

2.1.1. Determining Segmentation. The procedure for determining the segmentation of the formatives of these submatrices by examination of the vertical blocks of Matrix 9 is described in detail in the next several paragraphs.

Matrix 10. Emic Formatives for Person.

Person: $\quad 1 \quad 1,2 \quad 3$

Number:

$\mathrm{p}$

S

$$
-\mathrm{i}
$$

a- $-u$

w

ta $-a$

$-a$

Matrix 11. Emic Formatives for Number.

Person: $\quad 1 \quad 2 \quad 1,2 \quad 3$

Number:

$\begin{array}{lllll}\mathrm{p} & \mathrm{m}- & \mathrm{y}- & -\mathrm{m} & \mathrm{d}- \\ \mathrm{s} & -\mathrm{n} & \mathrm{y}^{-} & \mathrm{m}^{\prime} & \mathrm{n}-\end{array}$

Submatrices 10 and 11 have an identical arrangement of categories; the columns contain categories of person (1 speaker; 2 addressee; 1,2 speaker and addressee; 3 referent), which intersect with categories of number (p plural, s singular) in the rows. Emic formatives for person from Sets III and IV appear in the cells of Matrix 10, with hyphens indicating the position of the number formatives. Matrix 11 contains emic formatives for number from Sets III and IV in the cells, with hyphens indicating the position of the person formatives.

In Matrix 9, columns of person 1, 2 are covered with a ta block in both singular and plural; therefore ta is placed in the $\overline{1,2}$ 
vector of Matrix 10 as person 1,2 formative. Plural 1,2 is contrasted with singular by the interior $-m$ block; therefore $-m$ is placed in the cell at the intersection of plural with 1,2 in Matrix $\overline{11}$ as a plural formative. Singular with person 1,2 can be analyzed as consisting of either a zero alloformative, or ta without $m$. The second analysis has been chosen as preferable; it seems awkward to attribute the singular component intersecting with person 1,2 to zero when, by contrast with 1,2 plural, the singular component actually seems to be signaled by absence of the plural formative. Pike has adopted the use of an acute accent mark after the formative to indicate its obligatory absence. 14 Using this notation, formative $\mathrm{m}^{\text {' }}$ is placed in Matrix 11 as the singular formative which intersects with person 1,2. The submatrices for Sets I and II (not shown) contain no variants from the formatives seen in Matrices 10 and 11 in these categories.

Second person singular of Set $I$ is enclosed in a zero block in Matrix 9 and can be described as manifested by a zero alloformative for person 2 and singular, or by a different zero for each component. A third alternative may be preferable. The only overt formative which occurs in Set I with $2 \mathrm{~s}$ is $\mathrm{ka}$, which has been included with the horizontally extensive $\mathrm{ka}$ block of Matrix 9. This $\mathrm{ka}$ can be analyzed as portmanteau when occurring alone, containing semantic components of person 2 and singular as well as the component for Set I. However, since the $\mathrm{ka}$ formative is from a different formative layer, and in order to facilitate this description, the single zero alloformative will be used in this paper to represent both person and number components of $2 \mathrm{~s}$ in this set.

The person 1 formative of Matrix 9 is abstracted next. Since person formatives in the other cells are vowels and $m$ has already been determined as a plural formative intersecting with person 1,2 , although its position varies in relation to the person formative (i. e., it occurs before person 1 , but after 1,2 person), the $m$ - formative for plural is placed in Matrix 11 where plural intersects with person 1. Formative -i as person 1 (from the inner layer vertical block of lp--not to be confused with the horizontal outer layer $i$ block) is placed in the cell at the intersection of person 1 with plural in Matrix 10. There are no variants of formatives for lp among the four sets of pronouns; $\mathrm{mi}$ in vertical block $\mathrm{lp}$ of Matrix 0 is a vector-patterned formative, or morpheme.

Finally, from column ls of Matrix 9 the ls formative -an is abstracted. From the right hand column of Matrix 9, 3s, formative $\underline{n}$ has already been identified as a singular formative intersecting 
with person 3. Consistent with the analysis of the other formatives, the $-\underline{n}$ of $1 s$ is analyzed as indicating singular here as well. The vowe $\bar{l}$ is chosen as the person formative, although the order of the formatives varies here also (compare $1,2 \mathrm{p}$ with lp above), i. e., in $3 \mathrm{~s}$ the order is number formative followed by person formative, but here in $1 \mathrm{~s}$ the order is person formative followed by singular formative. Formative a- as person 1 is placed in Matrix 10 at the intersection of person 1 with singular. Formative $-n$ as singular is placed in Matrix 11 at the intersection of singular with person 1 .

Sets I and II have alloformative variants of $1 \mathrm{~s}$, seen in the broken vertical block of column is in Matrix 9. Set I variant is $-\mathrm{aq}, 8$ with the vowel formative retained, but $-\mathrm{q}$ as an alloformative of $-\mathrm{n}$ for singular. Set II variant is $\underline{\mathrm{ku}}$, analyzed as $\underline{k}-$ for singular and $\underline{\underline{u}}$ for person 1 .

2. 1. 2. Listing of Formatives. The alloformatives from all four sets of pronouns and their meanings, as described in the preceding paragraphs, are stated as follows, using the notation adopted by Pike. 16 ( $U$, to be read 'or', represents the union of two categories; $\Omega$, to be read 'and', represents the intersection of two categories.) Alloformatives have been listed from Matrix 9 in order from left to right by columns and from top to bottom by rows.

$\begin{array}{lll}\frac{\mathrm{m}}{\mathrm{i}} & = & \text { plural } U \text { singular. } \\ \frac{\mathrm{a}}{\mathrm{a}} & = & \text { person } 1 . \\ \frac{\mathrm{n}}{\mathrm{q}} & = & \text { person } \mathrm{U} \text { person 3. } \\ \frac{\mathrm{k}}{\mathrm{u}} & = & \text { singular. } \\ \mathrm{y} & = & \text { singular. } \\ \frac{\mathrm{na}}{\mathrm{w}} & = & \text { person } 1 \mathrm{U} \text { person 2. } \\ \underline{\#} & = & \text { plural. } \\ \frac{\mathrm{ta}}{\mathrm{d}} \underline{\underline{r}} & = & \text { person } 2 . \\ & = & \text { person } 2 \mathrm{U} \text { person 3) nsingular. }\end{array}$

2. 1. 3. Listing of Categories. In the above list, ambiguities are apparent; however, when categories of person and number intersect, these ambiguities are resolved. The categories are listed and described below from Matrix 9 in the same order as stated above. (A hyphen is used with the interesecting formatives to indicate order of occurrence.) 


$$
\begin{aligned}
& \text { person } 1=\underline{(i \cap} \underline{\underline{m-}}) \cup(\underline{a} \cap[\underline{-n} U \underline{-q}]) \cup(\underline{u} \cap \underline{k-}) \text {. } \\
& \text { person } 2=\left(\underline{u} \cap[\underline{y}-U \underline{m-}) U\left(\underline{w} \cap\left[\underline{n a}-U \underline{y^{0}}\right]\right) U(\underline{\#} \cap \underline{k a})\right. \text {. } \\
& \text { person } 1,2=\left(\underline{\text { ta }} \Omega\left[\underline{-m} U \underline{m^{\prime}}\right]\right) \text {. } \\
& \text { person } 3=(\underline{a} \cap[\underline{\mathrm{d}}-\sim \underline{\mathrm{r}}-\mathrm{U} \underline{\mathrm{n}}-]) \cup \underline{\#} \text {. } \\
& \text { plural }=(\underline{m} \cap[\underline{-i} U \underline{t a}]) U(\underline{y} \cap \underline{-u}) U(\underline{n a} \cap \underline{-w}) U \\
& \text { ( } \underline{\mathrm{d}} \sim \underline{\mathrm{r}} \cap \underline{-\mathrm{a}}) \text {. } \\
& \text { singular }=(\underline{\mathrm{n}} \cap[\underline{\mathrm{a}-} \mathrm{U} \underline{-a}]) \cup(\underline{\mathrm{g}} \cap \underline{\mathrm{a}-}) \cup([\underline{\mathrm{k}} \mathrm{U} \underline{\mathrm{m}}] \cap \underline{\underline{u}}) \\
& U\left(\left[\underline{y}^{\circ} U \underline{n a}\right] \cap \underline{w}\right) U\left(\underline{\# \underline{k a})} U\left(\underline{m^{\prime}} \cap \underline{\text { ta }-}\right)\right. \text {. }
\end{aligned}
$$

2. 1. 4. Matrix of Kernel Person and Number Formatives. As has been mentioned, the above statement includes the alloformatives for person and number for all four sets of pronouns. The emic formatives (morphemes) for person and number are displayed in Matrix 12, which represents the emic kernel ${ }^{17}$ of the pronoun structure and will be symbolized by $M_{k}$. At the level of this matrix, the ambiguities have disappeared. Each cell is filled by a different formative, a single-cell formative; Matrix 12 is an ideal matrix. ${ }^{18}$

Matrix 12. $\mathrm{M}_{\mathrm{k}}$--Emic Person and Number Formatives.

$\begin{array}{lllll}\text { Person: } & 1 & 2 & 1,2 & 3\end{array}$

$\mathrm{M}_{\mathrm{k}}=$ Number:

$\begin{array}{lllll}\mathrm{p} & \mathrm{mi} & \mathrm{yu} & \text { tam } & \mathrm{da} \\ \mathrm{s} & \text { an } & \text { w } & \text { ta } & \text { na }\end{array}$

The occurrence of the alloformatives for person and number in each of the pronoun sets has been described above, so that Set II pronouns can now be defined in the simple emic formula- $-M_{k}=$ Set II.

2. 2. Formatives of Aspect and Grammatical Relationships. The three outer layers of horizontal blocks in Matrix 9 have not 
been defined. The interior one of these is composed of blocks of $\underline{\mathrm{ka}}, \underline{\mathrm{t}}$, and $\mathrm{g}$; the middle layer is the block of $\underline{i}$ which occurs exterior to $\mathrm{ka}$ and $\mathrm{t}$, but interior to $\mathrm{g}$; and the exterior laye r contains blocks $\mathrm{n}, \mathrm{ku}, \mathrm{s}$, and ag. These outer blocks extend horizontally within the the rows of Sets IV, III, and I, but not Set II, which suggests a structural contrast between the first three sets and Set II. Set II has been defined as consisting simply of kernel pronominal formatives which are present in all four sets. Complex Sets IV, III, and I are derived sets.

2. 2. 1. The i Block. Set II pronouns substitute for substantive phrases indicating source. Pronouns of Sets IV, III, and I substitute within a clause for substantive phrases indicating relationships other than that of source. In Matrix 9, the middle layer formative $i$ block extends over a large area of these three sets. In Set I, formative $i$, which occurs word initially (except before $\mathrm{ka}$, and -aq of $\mathrm{ls}$, which will be explained later) marks this set as substitutable for a topic phrase in a clause. Set IV substitutes for a nonemphatic topic phrase in post-predicate position--but changing it to emphatic topic, or for an emphatic topic phrase in pre-predicate position. Pronouns of Set III occur only in oblique relationship within a clause, indicating that the semantic component of $i$ is modified by the occurrence of the oblique relationship component.

The analysis of $i$ as carrying the topic relationship component is interestingly paralleled by the identical shape of a free variant $i$, in fast speech, of the phrase marking particle yu, which marks the topic phrase within a clause.

The $\mathrm{i}$ block does not extend over person 1 and person 2 of Set I or ove $\bar{r} 3 s$ of Sets III and I. Third singular of Set I has no overt filler; formative $i$ is assumed to occur here as a zero alloformative. Third singular of Set III is completely irregular in its outer layer, which consists solely of $\mathrm{ku}$. This $\mathrm{ku}$ block is the only irregularity in the row of formative $\underline{n}$; therefore $\underline{k}$ is analyzed as an alloformative of $\underline{\mathrm{n}}$ and $\underline{\mathrm{u}}$ as an alloformative of $\underline{\mathrm{i}}$.

First person singular of Set $I$ is the only pronoun in the four sets which has only a bound clitic (suffix) form, i. e., -ag. Since the semantic component of formative $i$ is present here also, zero alloformative of $\underline{i}$ is assumed to occur here; and for the same reason, the zero alloformative of $i$ is also assumed to occur word initial before ka in Set I, columns lp, ls, 2p, and 2s. This analysis is illustrated in Matrix 13. An alternate solution would be to consider 
the ka portmanteau, carrying the topic phrase component as well as its particular component of aspect which is discussed below.

In formulas for the derivation of the different pronoun sets, the $\underline{i}$ formative semantic component will be symbolized by $t$, reflecting its topic marking function.

Matrix 13. Abstraction of $\underline{i}$ Block Showing Alloformatives.

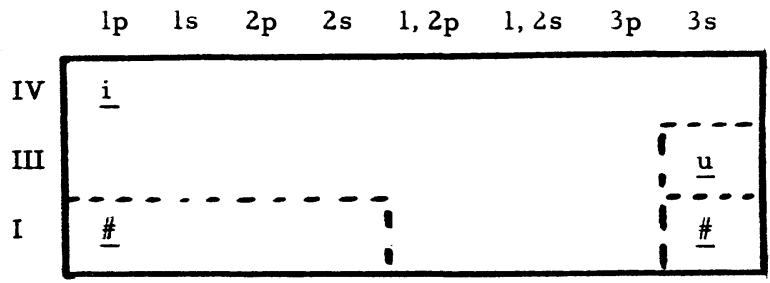

2. 2. 2. Blocks of $\underline{k a}, \underline{t}$, and $g$. Perhaps the most difficult to define of the horizontal outer blocks of formatives are the blocks of $\underline{\mathrm{ka}}, \underline{\mathrm{t}}$, and $\mathrm{g}$. These three blocks divide the columns; ka extends over person 1 and person 2 of Sets I, III, and IV, except ls of Set I where it is assumed that since the semantic component is present, a zero alloformative of ka occurs; $t$ extends over person 1,2 in these three sets, and $g$ extends over person 3 in Set IV only. The only internal clue as to the meaning of these formatives is their contrastive distribution, which suggests contrast of aspect.

There are other clues as to meaning from the affixation in the language; $\mathbf{k a -}$ is a productive morpheme which occurs prefixed to stems either alone or in combination with other affixes. The meaning of ka- varies according to types of stems with which it occurs; for example, with descriptive stems, i. e., adjectives, it forms nouns: baddì means 'small', kabaddì means childhood'; awân means 'none', káwán means 'absence'. 'Specific', 'definite', and 'superlative' are some of the glosses that have been used for ka-. With reference to the pronouns, the first two of these glosses may be pertinent to the ka block as a gloss for its aspect meaning in contrast to the aspect meaning of the formatives $t$ and $g$ described below.

The two remaining formative blocks of this interior horizontal layer are blocks of $\underline{t}$ and $g$. These are analyzed as alloformatives of 
one formative represented by morphophonemic $\underline{G}$ on the basis of the following morphoiogical data:

1. In prefixes ending in $\mathrm{g}$, such as mag-and ag-, the g completely assimilates to the initial consonant of the stem, forming a geminate consonant cluster. Single g is retained only with vowel initial stems. For example, pepperán means 'that which is to be fanned', plus ag-becomes appeppek 'the fan', or plus mag- becomes magatà 'to roof'. This morphophonemic change suggests that the pronominal formative $\underline{t}$ may be an assimilated $g$.

2. There is a nonproductive affix gi-which occurs with some stems either alone or in combination with other affixes. 'Nonspecific' and 'general' are used as glosses for gi-with certain stems; for example, nuáng means 'carabao', ginuáng means 'domestic fourlegged animals'. With some stems $-\mathrm{g-}$, an allomorph of gi-, occurs following ag-, which means 'an instrument'. The contrast of gi-with $\mathrm{ka-}$ is seen in the following examples: ammu means 'to know', gigiammuán means 'studying in school', kanammuán means 'comprehension'; ubobuk means 'word', aggubobuk (ag- plus -g-) means 'speech', kobobuk (ka- plus ubobuk) means 'reason for speaking'.

On the basis of the data, the $t$ formative, which occurs before pronoun formative person 1,2 beginning with initial $t$, is analyzed as an assimilated -g-, allomorph of gi-, containing the semantic component of 'general', and the g formative of Set IV in $3 \mathrm{p}$ and $3 \mathrm{~s}$ is included in this analysis. The $\mathrm{t}$ and $\mathrm{g}$ blocks are then brought together into a single $G$ formative block. Metathesis is assumed to have occurred between the $\mathrm{g}$ formative and the $\underline{i}$ formative, which occurs exterior to the blocks of ka and $\underline{G}$ except in $3 p$ and $3 s$ of Set IV.

However, there are some indeterminacies connected with this analysis. The categories of $3 p$ and $3 s$ is Sets I and III are not included in the $\mathrm{G}$ block. Should these two sets be included by postulating a zero alloformative of $\underline{G}$ ? Or is the person 3 category of $S$ ets I and III not included in this formative block because its semantic components of this class will be symbolized by a, reflecting the class meaning of aspect. 
Matrix 14. Abstraction of Blocks of ka and $\underline{\mathrm{G}}$ Showing Zero Alloformatives.

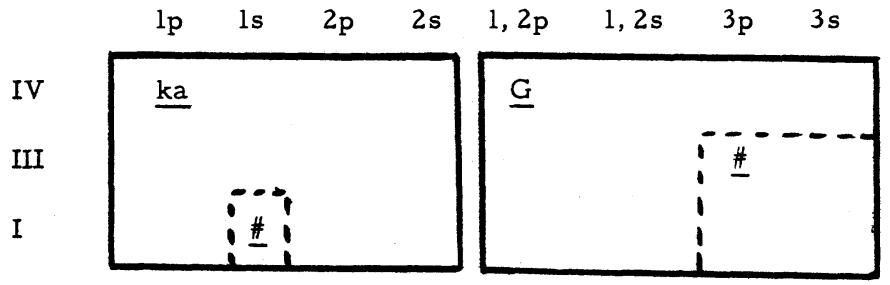

2. 2. 3. Derivation of Set I. Of the horizontal blocks of formatives, the occurrence of the interior and middle layers, ka and $\underline{G}$ and $i$, contrasts Set I pronouns with Set II. Since Set II pronouns have been defined in Matrix 12 as $\mathbf{M}_{\mathbf{k}}$, it is now possible to derive Set I by matrix multiplication, applying here the procedure outlined by Pike, 19 i. e., the kernel matrix is assigned a symbol-$\mathrm{M}_{\mathrm{k}}$; the factors $\mathrm{ka}$ and $\mathrm{G}$ are symbolized by a (for aspect factor), and $\underline{i}$ is symbolized by $\underline{t}$ (topic phrase); a derived matrix is the product of multiplication of a kernel matrix. The product of this multiplication (Formula 1 ) is a derived single row vector matrix identical with the third row down abstracted from Matrix 9 (i. e. , Set I pronouns), which will be labeled $\mathrm{M}_{\mathrm{t}}$ since this is the set which occurs as topic within a clause.

Formula 1. $\mathrm{M}_{\mathrm{k}} \cdot \mathrm{a} \cdot \mathrm{t}=\mathrm{M}_{\mathrm{t}}$

2. 2. 4 Blocks of $\mathrm{n}$ and $\mathrm{s}$. Yet remaining to be described are the exterior horizontal layers extending over Sets III and IV, which are composed of two mutually exclusive contrastive row vectors. The lower one may be represented by formative $\underline{n}$, which includes the alloformative $\mathrm{k}$ intersecting with $3 \mathrm{~s}$; the top row vector may be represented by formative $s$, which includes the alloformative ag intersecting with $3 \mathrm{p}$ and $3 \mathrm{~s}$.

The formatives of these blocks, $\underline{n} \sim \underline{k}$ and $\underline{s} \sim \underline{a g}$, carry the structural signals which contrast Sets III and IV respectively and indicate their syntactic relationships. Set III pronouns are substitutable for phrases in oblique relationship within a clause; the oblique relationship is the grammatical semantic component of $\underline{\mathrm{n}} \sim \underline{\mathrm{k}}$. The $\underline{\mathrm{s}} \sim \underline{\mathrm{ag}}$ of Set IV pronouns carries the semantic component of topic emphasis, and indicates substitutability of 
these pronouns for a topic phrase (Set I pronouns occur here as nonemphatic topic) or for an emphatic topic phrase, which occurs in pre-predicate position.

When a name is substituted for a pronoun in a topic phrase or an emphatic topic phrase (pre-predicate), the name is preceded by personal marking particle si. But this correlation of shape of pronoun formative for emphatic topic relationship with the shape of the personal marking particle indicating the same relationship is not paralleled in the case of oblique phrases; when a name substitutes for a pronoun in an oblique phrase position, it is preceded by the personal marking particle ka.

The personal marking particle ni occurs before names only in attributive relationship indicating source; only pronouns of Set II occur here.

2. 2. 5. Derivation of Sets III and IV. Set III pronouns can be derived by multiplying the matrix of Set I pronouns, $M_{t}$, by the constant factor $\underline{\mathrm{n}} \sim \underline{\mathrm{k}}$ (oblique relationship), which will be symbolized by o. The product of this multiplication (Formula 2) is a derived single row vector matrix identical with the second row down of Matrix 9 (i. e., Set III pronouns), and this matrix wiil be labeled $\mathrm{M}_{\mathrm{O}}$, reflecting its oblique grammatical relationship.

Formula 2. $\mathrm{M}_{\mathrm{t}} \cdot \mathrm{o}=\mathrm{M}_{\mathrm{O}}$

Similarly, Set IV pronouns are derived by multiplication (Formula 3) of $\mathrm{M}_{\mathrm{t}}$ by the constant factor $\underline{\mathrm{s}} \sim \mathrm{ag}$ (emphatic topic relationship), which will be symbolized by e. The resultant derived single row vector matrix is identical to the first row of Matrix 9 (i.e., Set IV pronouns), and is given the symbol $\mathbf{M}_{e}$, reflecting the emphatic component of the set.

Formula 3. $\mathrm{M}_{\mathrm{t}} \cdot \mathrm{e}=\mathrm{M}_{\mathrm{e}}$

3 Summary. The internal structure of four sets of Atta pronouns was graphically displayed in the matrices of Section 1. In Section 2 the semantic components of these pronoun sets were described and related to the grammatical constructions in which they occur

Using matrix multiplication, the derivation of the more complex Sets I, III, and IV from the kernel Set II was reduced 
to three simple formulas, reflecting the relationship of the sets to each other, both structurally and semantically. 


\section{NOTES}

1. Atta is a Negrito dialect of Northern Gagayan Province, Luson, Philippines. Data were gathered by Whittle and Lusted in the municipalities of Pamplona, Cagayan Province, and Allacapan, Cagayan Privince, during the years 1955-63.

2. See Otto Scheerer, "The Nabaloi Dialect," Ethnological Survey Publications, Manila, 1905, Vol II, Part II, pp. 113-117; Rufino Alejandro, A Handbook of Tagalog Grammar, Manila, 1947, Chapter 10; Andrew M. Nelson, A Grammar of the Cebuano Dialect, Ago Mimeograph Service, Cebu City, Philippines, 1954, Chapter 4; Morice Vanoverbergh, CICM, Iloko Grammar, Catholic School Press, Philippines, 1955, Chapter 5; Jose Hevia Campomanes, O. P. , Grammar of the Tagalog Language, circa 19th century, p. 16; Howard McKaughan, The Inflection and Syntax of Maranao Verbs, Manila Bureau of Printing, 1958, p.8.

3. David Thomas, in his "Three Analyses of the Ilacano Pronoun System, "Word, 2:204-208, 1955, breaks down some of the more complex Ilocano pronouns, and assigns meaning to the separated morphemes. He states (p. 205, footnote 6), "I have preferred to analyze these 'free pronouns' as bound pronouns suffixed to a particle of emphasis, rather than analyzing the total form as a free pronoun." McKaughan, op. cit., states, p 8, "Inspection shows that at least some of these sets consist of combinations of bound morphemes with perhaps allomorphs of pronominal basis... morphemes could be isolated in Sets I and II with an attempt to relate such morphemes to grammatical or lexical meanings. However, for ease of description and reference, we have listed the members of the paradigms as units without further analysis." Phyllis Healy in her An Agta Grammar, Manila Bureau of Printing, 1960, p. 16, states "... it is impossible and unprofitable grammatically to try to draw morphological boundaries within the forms of these pronouns..." Agta is a language closely related to Atta.

4. Kenneth L. Pike, Matrix Permutation and Conflation, presented under the title Matrix Rotation and Matrix as an Emic Unit, to the annual meeting of the Linguistic Society of America in 
New York, Dec. 29, 1962. He defines permutation as "any interchange of rows, or interchange of columns, or interchange of rows with columns, or interchange of cell components from inside to outside the matrix." (p. 2) Conflation is "the result of superimposition--of the blocks of formatives of the various submatrices." (p. 7).

5. As defined by Pike, op. cit., "A formative... is the phonological particle filling a cell of an emic matrix."

6. When Sets I and II occur in juxtaposition in the syntax some fusion occurs, forming a pseudo-Set V.

7. Leonard Bloomfield, in Language, 1933, terms plural pronouns like these in Tagalog respectively "exclusive first person plural" and "inclusive first person plural." Healy, op. cit., p. 15, terms person 1, 2 the inclusive person. For a handling of pronominal semantic components in Hanunóo, see Harold C. Conklin, "Lexicographical Treatment of Folk Taxonomies." IJAL, 28:2, Part IV, April, 1962, pp. 119-137. He presents in a cube diagram the "regular intersection of six components which comprise three simple oppositions." See Thomas, op. cit., for a comparison of three analyses of Ilocano pronouns, the third of which he recommends as adequate for Ilocano.

8. The following allomorphs occur: In Set I, Is, aq ngaq; aq occurs following consonants; ngaq occurs following vowels. In Set II, ls, ku q ; $\mathrm{ku}$ occurs following consonants; q occurs following vowels. In Set II, $\overline{2}$, mu $\sim \underline{m ;}$ mu occurs following consonants; $\underline{m}$ occurs following vowels.

9. These matrices do not include all the intermediary experimental permutations that were made. Only those are shown from which significant patterning developed.

10. These implications were discussed in Section 2.

11. Pike, op. cit., states, p. 21, "the single-celled formative may be called an ideal particle..."

12. Pike, "Language as Particle, Wave, and Field," The Texas Quarterly, Vol. II, No. 2, Summer, 1959, p. 38. "The view of language as made up of field sees language as functional, as a 
system with parts and classes of parts so interrelated that no parts xccur apart from their function in the total whole, which in turn occurs only as the product of these parts in functional relation to a meaningful social environment."

13. Pike, Matrix Permutation and Conflation, "The conventional simple morpheme of an inflectional type is isomorphic with a formative which fills every cell of one row of a matrix, or of one column of a matrix (but not both)... If we call either the full row or a full column a vector pattern in the matrix, then the simple inflectional morpheme is a vector-patterned formative."

14. Pike, 오. cit., Section I, C., (7b) and (8).

15. The distribution of these two formatives can be phonologically defined: - $\underline{u}$ occurs following a consonant; - $w$ occurs following a vowel. This should not be interpreted to mean that there are no vowel clusters in the language.

16. Pike, loc. cit.

17. Pike, "Dimensions of Grammatical Constructions," Language, 38:221-44, 1962.

18. Matrix Permutation and Conflation.

19. "Dimensions of Grammatical Constructions," p. 226. 
http://www.jstor.org

\title{
LINKED CITATIONS \\ - Page 1 of 1 -
}

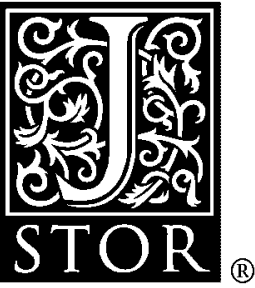

You have printed the following article:

The Use of Matrix Technique in an Analysis of Atta Personal Pronouns

Ruth Lusted; Claudia Whittle; Lawrence A. Reid

Oceanic Linguistics, Vol. 3, No. 1, Papers in Philippine Linguistics. (Summer, 1964), pp. 138-160.

Stable URL:

http://links.jstor.org/sici?sici=0029-8115\%28196422\%293\%3A1\%3C138\%3ATUOMTI\%3E2.0.CO\%3B2-3

This article references the following linked citations. If you are trying to access articles from an off-campus location, you may be required to first logon via your library web site to access JSTOR. Please visit your library's website or contact a librarian to learn about options for remote access to JSTOR.

\section{Notes}

\author{
${ }^{17}$ Dimensions of Grammatical Constructions \\ Kenneth L. Pike \\ Language, Vol. 38, No. 3, Part 1. (Jul. - Sep., 1962), pp. 221-244. \\ Stable URL: \\ http://links.jstor.org/sici?sici=0097-8507\%28196207\%2F09\%2938\%3A3\%3C221\%3ADOGC\%3E2.0.CO\%3B2-I
}

NOTE: The reference numbering from the original has been maintained in this citation list. 